\title{
Hazard and risk assessment for indirect potable re-use schemes: an approach for use in developing Water Safety Plans
}

\author{
Angelina Dominguez-Chicas ${ }^{\mathrm{a}, \mathrm{b}}$, Mark D. Scrimshaw ${ }^{\mathrm{a}^{*}}$ \\ ${ }^{\text {a }}$ Institute for the Environment, Brunel University, Uxbridge, Middlesex UB8 3PH, UK \\ ${ }^{\mathrm{b}}$ Programa Ambiental, Instituto de Ingeniería y Tecnología, Universidad Autónoma de Ciudad Juárez, Av. Del Charro \\ 450 Nte. Partido Escobedo, Ciudad Juárez, Chihuahua, México, C.P. 32310 \\ * Corresponding author. Tel.: +44 (0)1895 267299; fax +44 (0)1895 269761 E-mail addresses: angelina.dominguez- \\ chicas@brunel.ac.uk (A. Dominguez-Chicas), mark.scrimshaw@brunel.ac.uk (M. D. Scrimshaw).
}

Key words: Water scarcity; Augmentation; Risk assessment; Chemicals; Heatmap

\begin{abstract}
This paper describes research undertaken to develop an approach for undertaking an initial hazard assessment and risk characterisation for a proposed indirect potable reuse scheme, as part of the water safety plan recommended by the by the World Health Organization. The process involved a description and evaluation of the catchment, which was the sewerage system supplying the sewage treatment works that would provide the effluent to supply the pilot scale indirect potable reuse water treatment plant. Hazards, sources and barriers throughout the proposed system were identified and evaluated. An initial assessment of the possible hazards, highlighted chemical hazards as predominating, and assessment of risks, using a heat map as output, categorised most hazards as medium or high risk. However, this outcome has been influenced by a precautionary approach which assigned a high likelihood to the occurrence of hazards where no data was available on their occurrence in the system. As more data becomes available, and the waster safety plan develops, it is anticipated that the risk heat map will become more specific. Additionally, high quality targets, to drinking water standards, have been set, although water from the potable reuse plant will be discharged to receiving waters where it will undergo natural attenuation prior to further treatment to potable standards before distribution. The assessment has demonstrated the usefulness of the approach where data is initially limited, in generating a heatmap allowing for prioritisation of hazards to a practical level.
\end{abstract}




\section{Introduction}

The World Health Organization guidelines for Water Safety Plans (WSPs) are based on the human health risk assessment of the potable water supply chain, from the catchment to the customer, considering the hazards within the system utilizing a multi-barrier principle (Davison et al., 2005). The approach takes into account issues related to the control, monitoring and validation of the whole water supply process. The WSP methodology is focused on conventional drinking water supplies, and evaluates the 'failure modes and effects analysis' (FMEA) of the system, in relation to the risk of producing unsafe water, with attention to microbial and chemical hazards (Hamilton et al., 2006). As part of the WSP, the whole supply process involved is documented, including management practices and quality assurance schemes that ensure the sound design, operation, and monitoring of the water supply chain, from resource to customer (Davison et al., 2005; WHO, 2006).

As a result of mounting worldwide water stress, the reuse of wastewater for potable purposes is increasing for the augmentation of supply, or protection of available natural sources of drinking water (IWA, 2008). It is possible to split potable reuse schemes into two categories, direct, where highly treated wastewater is supplied directly to a drinking water treatment plant, and this only occurs at one place in the world currently, Windhoek in Namibia. or indirect, where it is discharged into a surface water that is later subsequently used as a water source. Indirect potable reuse (IPR) is defined as "the abstraction, treatment, and distribution of water for drinking from a natural source water that is fed in part by the discharge of wastewater effluent" (NRC, 1998).In addition, IPR can be further subcategorised as "unplanned" where treated wastewater is reabstracted downstream due to historic legacy or "planned" where the process is actively managed. More than fifteen planned IPR facilities are already operating worldwide, some of which have been functioning for over 20 
years (Asano et al., 2007; Rodriguez et al., 2009). To date, neither environmental or public health problems have been detected, and such schemes are becoming more common as available water becomes increasingly scarce (Del Pino and Durham, 1999; Singapore Public Utilities Board, 2002; Asano et al., 2007; IWA, 2008). Evaluation of planned IPR schemes, inline with the WSP framework, should encompass comprehensive health assessment and risk management strategies, which take into account the unique risk characteristics of IPR schemes, such as:

- complexity and variability in composition of the source of water;

- limited knowledge of health effects related to individual chemicals and mixtures of hazards;

- $\quad$ public acceptance of the end product; and

- the need for greater support for planners and engineers during decision making, such as the level of monitoring and testing required and the prioritisation of corrective and preventive actions (IWA, 2008).

Although there are a few key guidelines (Davison et al., 2005; NRMMC and EPHC, 2006a) and documented experiences for hazard and risk assessment in IPR projects (Crook and Surampalli, 1999; Crook, MacDonald and Trussell, 1999; Rodriguez et al., 2007a; Rodriguez et al., 2007b), to date these have not been undertaken within the framework of a WSP. This work describes the first attempt, undertaken as part of a research project, at implementing a WSP for an IPR system in the early stage of development. It covers the three first three modules outlined in the WHO WSP Manual (WHO, 2005); assembly of the work team; documentation and description of the system; and hazard identification and the risk characterisation. The IPR scheme for which this methodology has been developed is being evaluated by a UK water utility serving a large metropolitan area for augmentation of the drinking water supply. The scope of this work is the consideration of the sewage catchment, through the conventional activated sludge sewage treatment works (STW) and 
the pilot scale IPR treatment process, with the end point being the product from the IPR plant. Further barriers, following discharge and subsequent abstraction, although of concern in a full WSP, are not considered in this hazard and risk characterisation.

\section{Work team and documentation}

The first stage of assessing the implementing a WSP approach for a potential IPR scheme was undertaken by the main author as a research study with guidance from the water utility where the IPR pilot plant was under evaluation. The key types of expertise that fed into the work included that from the research team responsible for designing and operating the pilot plant, composed of scientists and engineers with a range of skills covering water reuse including membrane technology and water quality. In addition, staff from other departments of the company were consulted for their relevant expertise in key areas such as operational water safety plans, water and waste water plant performance, trade effluent, sewerage system maintenance and catchment modeling. Input from the various experts helped describe the system and aid hazard assessment and risk characterization.

Information from internal sources within the water utility and from the public domain was consulted for documented experiences from similar processes. Information from internal sources included that from the consulted experts described above. Public domain information sources included government and research organisations (Environment Agency, British Geology Survey, British Meteorological Office, National Health Service, Drinking Water Inspectorate, Greater London Authority planning documents) and for a range of information on the removal of contaminants in advanced treatment processes, scientific journals and reports.

\section{Hazard assessment and risk characterisation}


The initial assessment of the hazards and the risk characterisation took into account the limited amount of water quality, technical and operational data available. In addition, an approach which evaluated expert opinion, within and external to the water utility, along with internal and public domain data was followed. This involved a description and evaluation of the system, followed by identification and assessment of hazards and hazardous events, and their risk characterization. The IPR system was described in terms of activities and their related hazards, potential hazardous events and failure modes (FMs) that may occur in the water supply chain. Such hazards and events may represent a risk by presenting a challenge to the treatment processes or result in operational problems within the water supply chain.

Unlike a traditional water supply, the IPR scheme utilises the sewage catchment as its source of water and three key barriers in this chain were identified as the catchment, the conventional activated sludge STW (AS STW) and the IPR water treatment process (IPR WTP) (Fig. 1). The description of the first barrier, the sewerage catchment, used information on activities undertaken in the catchment along with their related hazards. That of the subsequent barriers, the AS STW and the IPR WTP, covered the processes which turn the source into reclaimed water that meets acceptable standards for augmenting raw water supplies. A summary of key facts and operational parameters relating to these three barriers is presented in Table 1 . These three barriers are effectively additional factors to be considered in relation to the existing treatment processes following abstraction from the receiving waters.

\subsection{The sewerage catchment barrier}

The raw water for the IPR system will be sourced from an urban catchment, with minimal agricultural but significant industrial activity. The sources of wastewater within this urban catchment were classified into ten further sub-catchments to facilitate the identification of hazards: 
- domestic

- legal traders

- illegal traders

- storm run-off

- hospitals and laboratories

- green areas (agricultural, parks and wildlife)

- urban buildings

- $\quad$ sewerage network

- hazardous events (flooding, fires, spills)

- planned future activities.

Table 1. Characteristics and operational parameters of the three barriers (the catchment, the AS STW and the IPR WTP).

\begin{tabular}{|c|c|c|}
\hline & Parameter & Details \\
\hline $\begin{array}{l}\text { 1. The sewerage } \\
\text { catchment }\end{array}$ & Industrial sector & $\begin{array}{l}\text { Area of approx. } 400 \mathrm{~km}^{2} \\
\text { Annual rainfall } 760 \mathrm{~mm} \\
30 \% \text { combined sewers, with limited infiltration } \\
\text { Metal electroplating; wholesale and service of } \\
\text { printers, radioactive substances (medical use), } \\
\text { non ferrous metals, waste incineration, } \\
\text { manufacture and supply of pharmaceuticals, } \\
\text { chemical and allied products. }\end{array}$ \\
\hline 2. The AS STW & Process & $\begin{array}{l}\text { Population equivalent approx. } 850,000 \\
70 \% \text { domestic flow } \\
\text { Consented flow of approx. } 450,000 \mathrm{~m}^{3} / \text { day } \\
\text { Average flow } 200,000 \mathrm{~m}^{3} / \text { day } \\
\text { Nitrifying activated sludge } \\
\text { (sludge age } 8-10 \text { days). }\end{array}$ \\
\hline 3. The IPR WTP & $\begin{array}{l}\text { Size } \\
\text { Pre-screening } \\
\text { Micro-filtration } \\
\text { Reverse osmosis } \\
\text { Advanced oxidation }\end{array}$ & $\begin{array}{l}600 \mathrm{~m}^{3} / \text { day } \\
500 \mu \mathrm{m} \text { filter } \\
5 \mu \mathrm{m} \text { pore size, } 85-95 \% \text { recovery } \\
\text { Flux } 17-20 \mathrm{~L} / \mathrm{m}^{2} / \mathrm{h} \\
75-85 \% \text { recovery } \\
\text { UV dose range: } 300-400 \mathrm{~mJ} / \mathrm{cm}^{2} \\
\mathrm{H}_{2} \mathrm{O}_{2} \text { dose range: } 2-10 \mathrm{mg} / \mathrm{L}\end{array}$ \\
\hline
\end{tabular}


These sources of wastewater were further delineated into a total of 42 sub-categories, for example domestic inputs were specified as either regular or exotic sewage. Out of 116 traders within the catchment, twenty six traders, predominantly from the metal finishing and food production industries, were classified by the water utility trade effluent (TE) team as 'risk traders'. This was based on an assessment of their activities, historical fulfilment of consented discharges, and procedures in place to manage unplanned discharges on site.

The hazards were classified as microbiological, physiochemical, nutrients, and chemicals. Chemicals were sub-classified as inorganic, metals (as a separate group to other inorganics), pesticides, endocrine disrupting compounds (EDCs), chlorinated solvents, disinfection by-products (DBPs), pharmaceuticals, other organics, and radiologicals. Hazards taken into consideration were those listed in national and international environmental and drinking water regulations (EEC, 1976; Defra, 2002; EC, 2006; NRMMC and EPHC, 2006b; WHO, 2006), those associated with specific activities in the catchment and those linked with health concerns expressed within the scientific literature and by experts, such as the TE team. Specific hazards of interest to the TE team, on the basis of historical infringements, were copper, nickel, cadmium, and arsenic. In addition to these four metals, chromium, lead, mercury, silver, zinc, toluene, cyanide, suspended solids and sulfides, along with oils and greases were identified by the TE team. Additionally, consideration of historical occurrence in receiving waters in the catchment as identified in the Environment Agency Pollution Inventory, also highlighted and a range of pesticides and other substances (Environment Agency, 2009). Assessment of other catchments may result in other classifications, which would be of greater relevance to the sources.

The sewerage system in the catchment consisted predominantly of combined sewers (75\%), and it was considered that discharges within the catchment would be impacted during rainfall events. Such 
impacts were considered as being likely to result in three possible consequences, dilution of hazards associated with dry weather flow, through transport of contaminants in run-off, and by increasing the flow rate through the system (Bannerman et al., 1993; Yuan et al, 2001; Kasprzyk-Hordern et al., 2008). The possibility of the release of hazards through point source discharge as single events within the catchment was encompassed utilising modelling, and the influence of four waste sites located in or near the catchment area was taken into account as they were either close to, or within, the run-off pathways known to occur during flooding events.

\subsection{The AS STW barrier}

The AS STW treats crude sewage to meet consents for discharge to the receiving water course. The wastewater passes through inlet screens, followed by primary settlement after which the settled sewage flows into the aeration tanks, where aerobic biodegradation of organic matter and ammonia takes place. Finally wastewater flows into the secondary settlement tanks, from which the final effluent is produced, a proportion of which flows to the pilot scale IPR plant (Fig. 1). The total time of residence through the AS STW is approximately 21 hours. For the purposes of the WSP no additional hazards were deemed to be added during wastewater treatment, as any inputs, such as nitrate produced through conversion of ammonia, were already included within the assessment of the catchment. The addition of polyelectrolyte to dewater sludge, with liquors returned to the crude sewage flow, was not deemed to represent a hazard based on available safety data.

\subsection{The IPR WTP barrier}

A proportion of the final effluent from the AS STW will be treated to a high quality in a pilot scale IPR WTP consisting of pre-screening, microfiltration (MF), reverse osmosis (RO), and an advanced oxidation process (AOP) utilising UV radiation and hydrogen peroxide. Subsequently, it is planned that the highly treated effluent will be returned to either surface water or potentially used to 

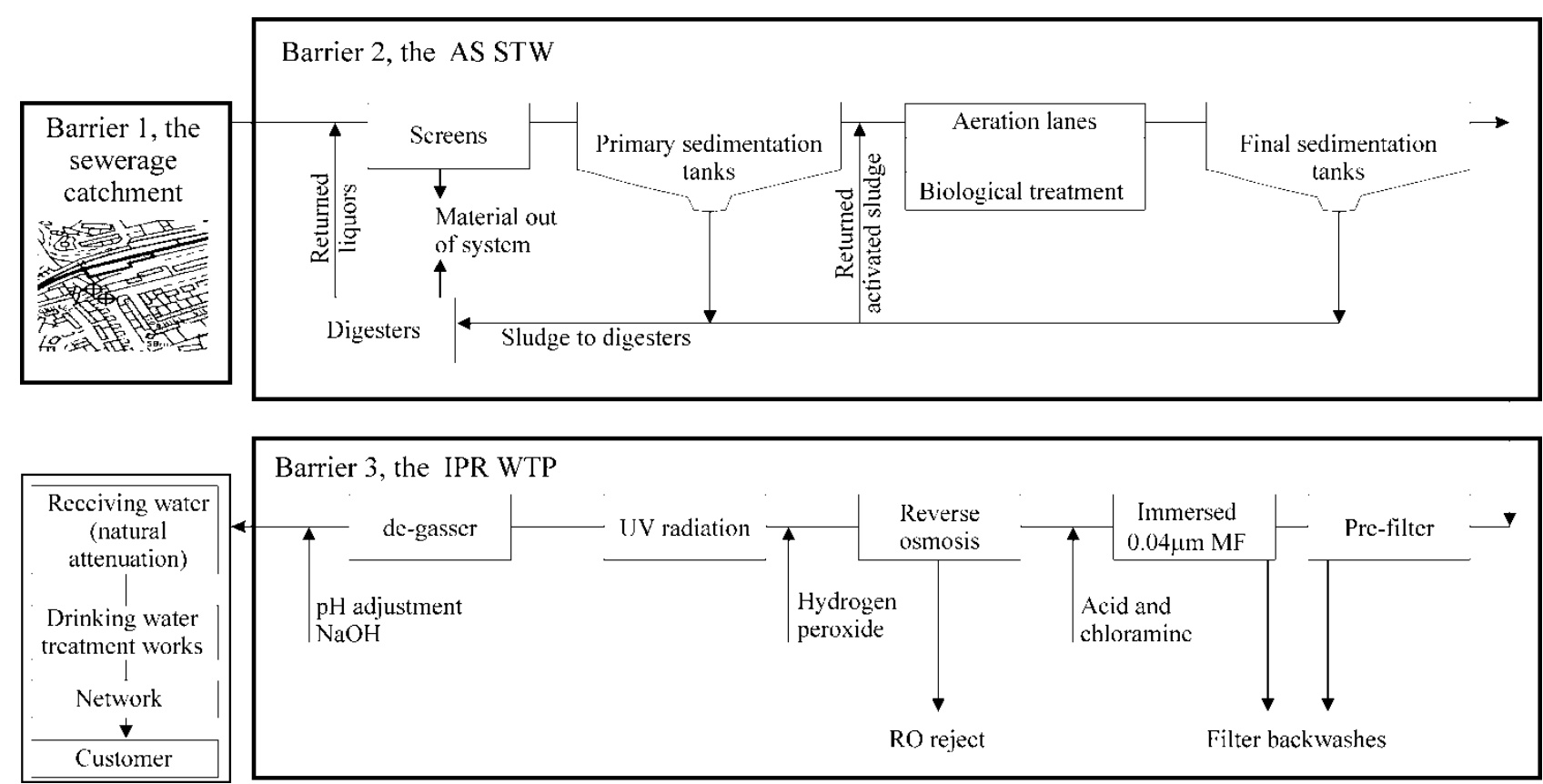

Fig. 1 - Schematic of the IPR drinking water supply. The WSP developed here was focussed on three barriers, the sewage catchment, activated sludge sewage treatment works (AS STW) and the pilot scale indirect potable reuse water treatment plant (IPR WTP).

recharge groundwater. Chloramine solution will be used to minimise biofouling of membranes, sulphuric acid will be used to minimise scaling of the RO membrane, and sodium hydroxide to correct the $\mathrm{pH}$ of the final treated water. The total time of residence of the water in the IPR WTP is approximately 2 hours. The final IPR system is proposed to be designed such that it is not a closed loop in that the reject and waste streams will not be returned to the head of the works but discharged to an alternative sewage treatment works in another catchment

\section{Identification and assessment of hazards and hazardous events}

Specific information about the main activities in the system along with their hazards were listed in a series of spreadsheets together with the main consequences (effects of their occurrence) downstream for each barrier. Assessment of the significance of failures involved the analysis of the consequences on the treatment processes or the quality of the final product. This process resulted in a list of hazards and hazardous events, which was used as a basis for the risk assessment process. 
Modelling was also undertaken to obtain the distribution of a point discharge of a hazard throughout the sewer network to the inlet of the STW using a validated hydraulic model already developed by the water utility with InfoworksCS (Wallingford Software, Wallingford, UK).

\subsection{Assessment of the sewerage catchment}

The outcome of an initial assessment of the catchment resulted in the identification of 490 potential hazards, linked to the ten sources of wastewater identified within the catchment. These hazards were prioritised by further consultation within the company and with external advisors, and reduced to 223 hazards for more detailed assessment. This prioritising process took into account national and international regulations, technical information for the individual stages of the water treatment process, and products used and manufactured within the catchment. The hazards continued to be classified into the four categories, microbiological, physicochemical, nutrients and chemicals, with the last group being subdivided into other categories as shown in Fig. 2. Analysis of the distribution of hazards between these categories identified that chemical hazards dominated in number, accounting for 193 of the 223 identified. Of these 193 chemical hazards pesticides contributed 67, "other organics" 35 and metals 30 . However, pesticides were associated with fewer sources $(<10 \%$ of the total number of sources) than compounds classified as "other organics" and metals, which were each associated with over $90 \%$ of the possible sources identified within the catchment. Microbiological hazards were relatively low in number and associated with few sources.

The assessment of the hazards and hazardous events are also being incorporated into a conceptual model (Fig. 3), where failures to achieve operational or water quality targets, described as FMs, are linked to the consequence of such a failure, the effect modes (EMs). The indicators described are the basis for the control of the process and are factors which could be taken into account when investigating the risks associated with key FMs. For instance the WSP framework recommends the 


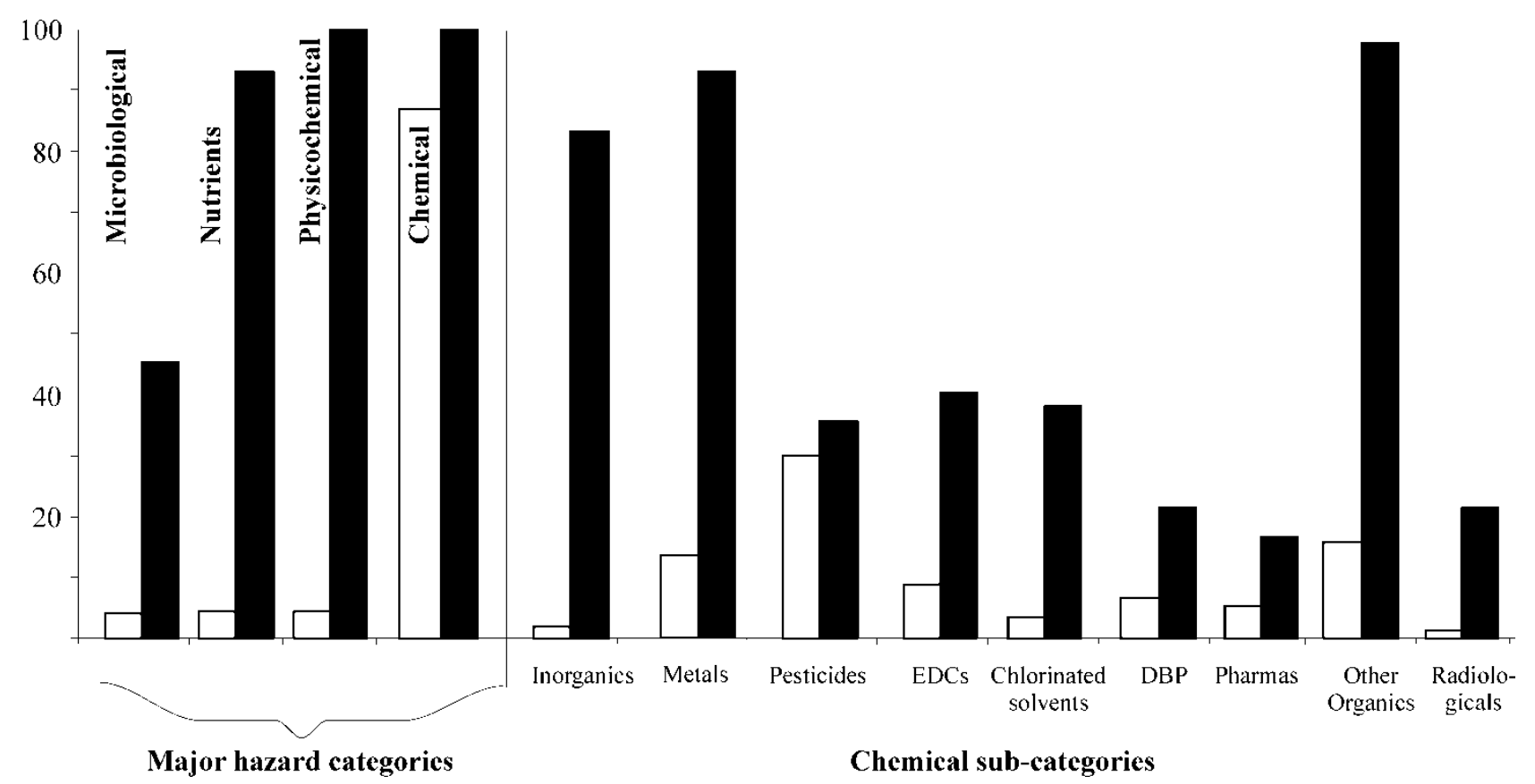

Fig. 2 - Relative contribution of each major hazard category to the total number of hazards ( $\square$ ) and percentage of sources within the catchment with which each hazard group was associated ( $\mathbf{\square})$.

assessment of the system in terms of what may cause hazards and hazardous events, and subsequently control and operational limits are identified and established to track the performance of the processes (Davison et al., 2005). Examples of this type of approach can be found in WSP developed for water supply (Guan, 2008; Simazaki, 2008), hospitals (Dyck et al., 2007) and the food processing industry (Casani and Knøchel, 2002). For example, should there be a case of 'disposal of hazards', described as FM-1 in the model (Fig. 3), this would be expected to result in a range of possible effects (EMs), the consequence of which, is described as the indicator. To date, relevant indicators to take into account have been identified as I-1 to I-6 in the model for the catchment, although this is an iterative process and the model is still being refined. To evaluate the significance of one of these indicators (I-3), the time taken for a hazard to reach the STW, and the possible impact of dilution (I-4), the distribution of a point discharge was evaluated using the InforworksCS model. 


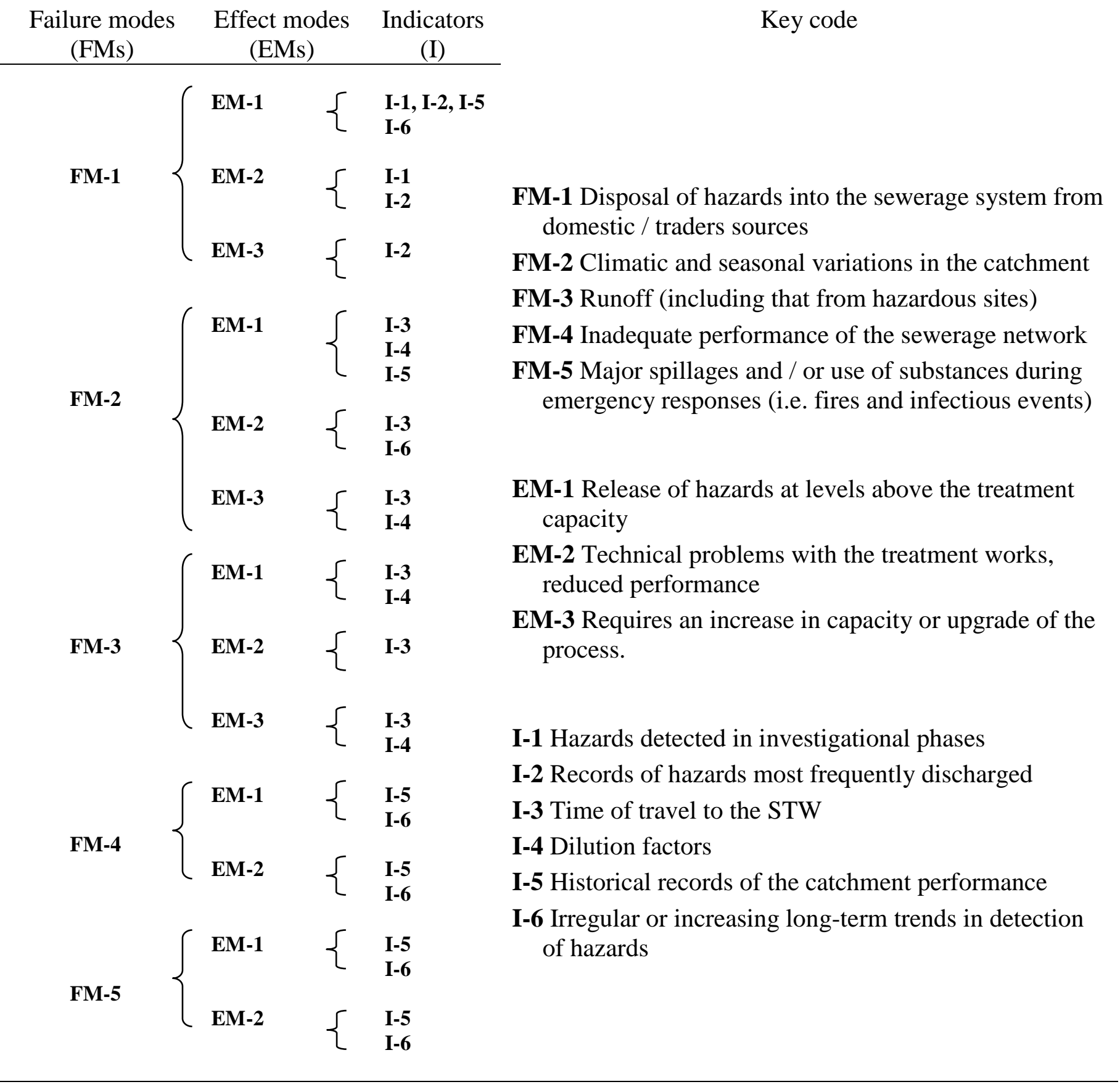

Fig. 3 - An initial conceptual model of failure modes, effect modes and their associated indicators as identified in the catchment for the IPR scheme which may be developed within the WSP.

\subsection{Modelling of the distribution of a point discharge}

The modelling investigated a hypothetical point discharge of a water soluble compound occurring over a period of one hour. Results indicated that broadening of the discharge during transit resulted in the event lasting between 80 to 215 minutes at the inlet to the STW. A comparison of the event 
occurring during dry or wet weather events determined that hazards would reach the entrance of the treatment works more rapidly during dry conditions than during storm conditions, as a result of water backing up in the system during rainfall events. This effect was more pronounced at locations farthest from the STW, and at $5 \mathrm{~km}$ or less, little delay would occur during storm flows. Modelling of such events enhanced the basic WSP by giving an assessment of the time available to make operational decisions at the STW or in the IPR WTP if mitigation measures are required to reduce risks.

\subsection{Assessment of the AS STW and IPR WTP}

Historical records of the conventional STW showed that the removal of basic parameters met performance targets. The robustness of the STW was also demonstrated by a decrease (from $60 \%$ to $38 \%$ ) in exceeding reporting thresholds for a range of other parameters between 2001-2005 (Envionment Agency, 2009). Overall, the chemicals were the most significant of the four categories of hazards identified in relation to possible failures at the STW (Fig. 4), although this was based on a literature review where a high likelihood of occurrence was used when real data on occurrence was absent. The assessment of the AS STW indicated that few microbiological hazards will be linked to failure modes, which was considered to be a result of the high quality of the effluent from the AS plant in relation to these parameters.

The hazards representing a challenge to the IPR WTP were evaluated using site specific water quality data from the effluent of the AS STW, and where not available, data from the literature (Davison et al., 2005; NRMMC and EPHC, 2006c; Asano et al., 2007; Metcalf and Eddy, 2007). The performance of the processes in relation to the removal of contaminants was evaluated by reference to the published literature on advanced treatment processes, and this was incorporated into the risk assessment. Again, outcomes in relation to the contribution of each of the hazard categories 
to failures is shown in Fig. 4. Of all the hazards identified, 67\% contributed to FMs. The majority of these were chemical hazards (53\%), a total of 130 possible chemical hazards associated with FMs based on the limited information on their occurrence available. Compounds included in this group were metals, pesticides, a range of other organics, and DBPs. The specific causes of FMs in the IPR WTP were assessed to be hazards associated with disinfection (DBP) (48\%) and passing through the RO membrane (14\%). This outcome may be a result of a precautionary approach being taken in this first iteration of the WSP, whereby a high likelihood of occurrence of a hazard was assigned when limited (or no) data was available and as more monitoring is undertaken, it is anticipated that this outcome will change. In the same manner as for the catchment, the evaluation of the hazards and hazardous events that may occur within the AS STW and the IPR WTP, and associated effects, are planned to be developed into a conceptual model.

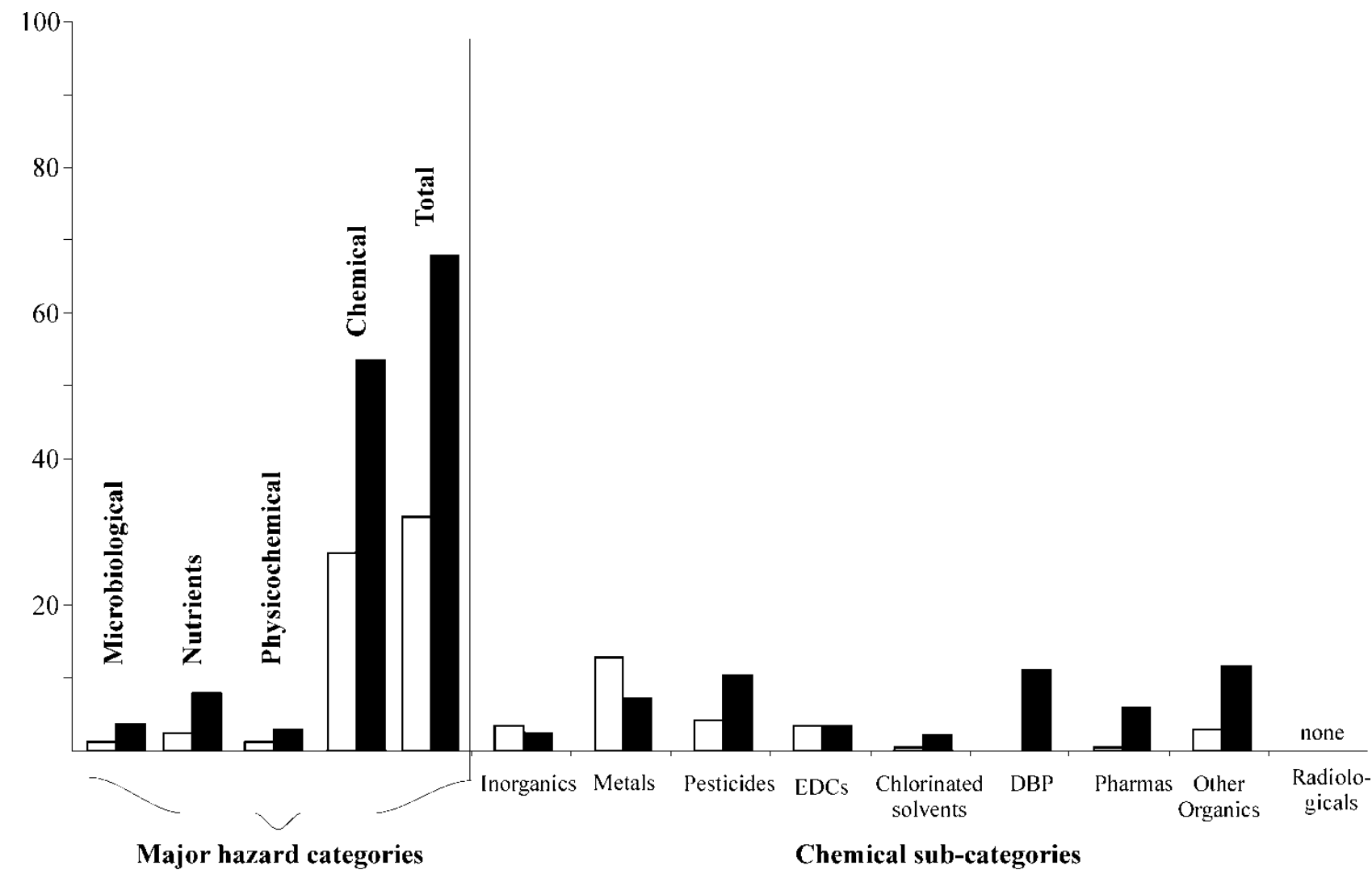

Fig. 4 - The percentage of hazards in each category related to failure modes at the AS SWT ( $\square$ ) and at the IPR WTP (घ). 


\section{Risk characterization of the hazards and hazardous events}

Within the semi-quantitative risk assessment procedure that forms part of the WSP (Davison et al., 2005), the risk $(R)$ is defined as the product of the likelihood of any hazard at a certain point of the process $(L)$, and the consequence $(\mathrm{C})$ downstream for the performance of the water supply

$$
R=L \times C
$$

The estimated risk for each hazard was classified as high, medium or low level, and all the resulting risks displayed in a risk heat map. This was undertaken in order to track the removal or control of risks along the IPR element of the drinking water supply chain, and facilitate the measurement of the effectiveness of risk management strategies. Initially this was an estimation of the premitigation and post-mitigation risks at each barrier.

A risk matrix with scores was produced, where $L$ and $C$ were both assigned a score (of 1 to 5 ), with 5 being the most likely hazard or most serious consequence. Assessment of the likelihood of a hazard took into account historical data on concentrations and frequency of detection at the entrance of the barrier, either as a result of typical activities or a failure in the previous barrier of the system. It also took into account the variability of the concentrations at the entrance of the barrier, and the ability of the processes that make up the barrier to mitigate the hazard. Consequences were related to the impacts of producing water of inadequate or variable quality, failing to achieve the technical requirements for the correct functioning of the system, and adverse implications to public health (acute and chronic effects).

The final outcome of the risk characterisation, based on estimations of the quality of the final treated reclaimed water, on the basis of published removal rates for the AS STW and the IPR WTP, quantified using Equation (1), was a 5 by 5 grid heat map (Fig. 5). The definitions for each of the likelihoods and consequences described in the heatmap are provided in supplementary informations, Tables S1 and S2. This risk characterisation will be refined as further data and hazard information 


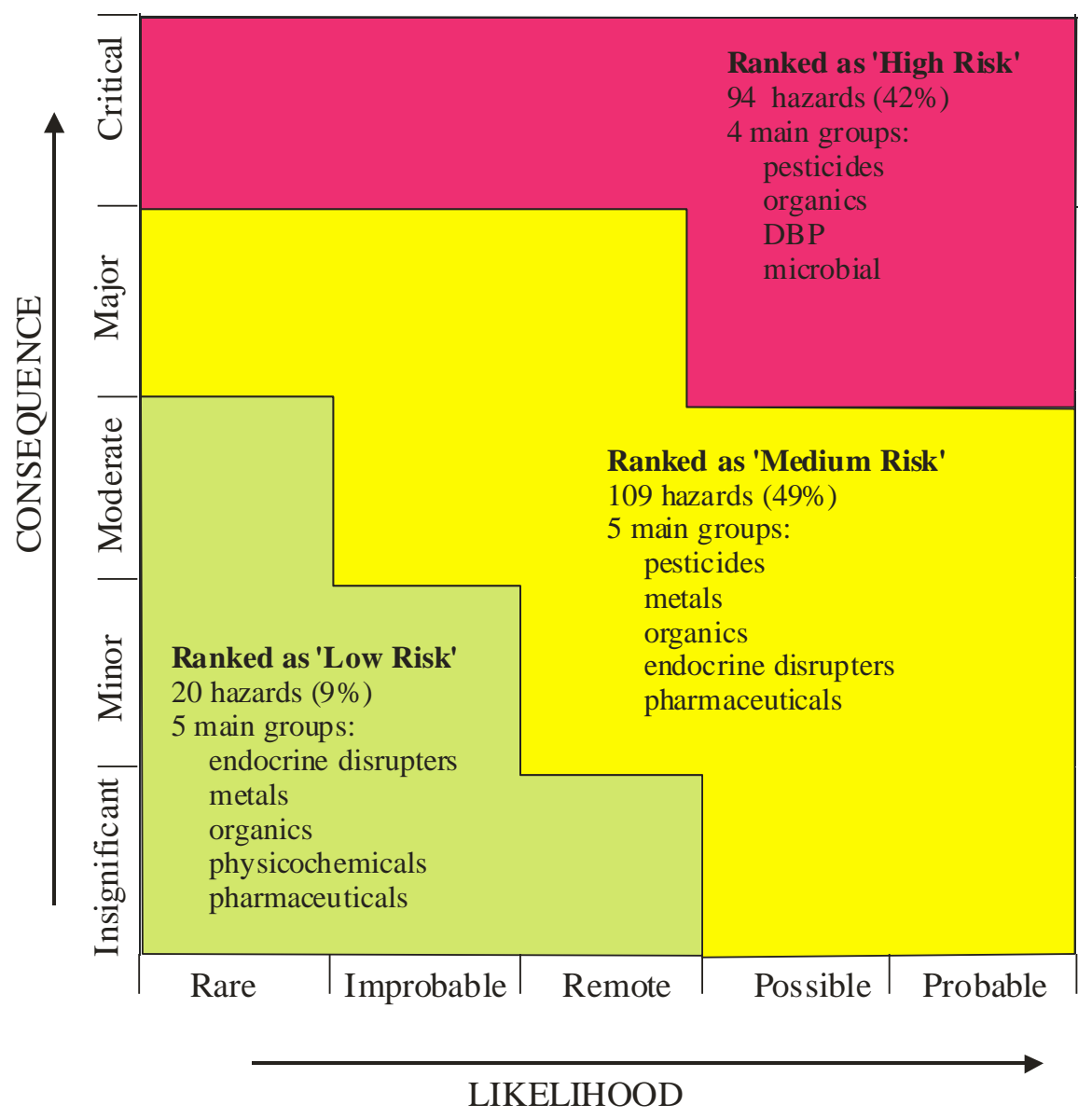

Fig. 5 - The heat map produced as a result of the WSP risk assessment based on estimated likelihoods of occurrence. The output will be refined during subsequent iterations.

becomes available. In the heat map, the likelihood of an event (hazard) is presented as increasing on the $x$-axis, and increasing severity of the consequence on the y-axis. Of the 223 parameters evaluated, $9 \%$ were assessed as low risk, $49 \%$ medium risk, and $42 \%$ as high risk. Microbiological hazards, although small in total number (Fig. 2), were ranked as high risk as a result of the lack of data on their occurrence and the high consequence that has initially been associated with them. Examples of the prioritised hazards, many of which are ubiquitous contaminants in the environment, and not site specific, are listed in supplementary information, Table S3. This initial assessment is based on a conservative evaluation of the likelihood of occurrence, due in the main part to a lack of real data, however, as more data becomes available, it is anticipated that the 
number of parameters identified as high and medium risks will be expected to decline with further refinement.

Of the 94 parameters characterised as high risk, some resulted in operational risk, such as membrane fouling and others were indicative of hazards potentially exceeding values in drinking water guidelines. However, it is important to put such outcomes in context, as for many hazards including pesticides, organics, pharmaceuticals, metals, chlorinated solvents and DBPs a lack of data on removal rates resulted in precautionary values being used for the initial assessment and as monitoring of the process is undertaken, the outcomes of the risk characterisation will be refined. Such outcomes should also be placed in the context of the final treated, reclaimed water, being discharged to a receiving water, where natural attenuation (Gurr and Reinhard, 2006), will precede further treatment following abstraction as part of the overall IPR scheme.

\section{Recommendations for monitoring and refinement of assessment}

The heat map was the result of an initial estimation of the potential risk posed by hazards identified as potentially being present within the catchment for the IPR WTP. Further refinement of the assessment, that has been produced within the limitations of available information, will be undertaken using data generated from further monitoring of the pilot scale plant presently being operated. Water quality monitoring throughout the supply chain will be undertaken to increase confidence in the quality of the product, based on a list of selected parameters included in a "water quality envelope' defined for the IPR system. The proposed water quality envelope consists of 74 parameters that are either:

- of concern for the IPR system due to their low or variable removal rates

- detected in high levels at the entrance to the IPR WTP

- related to historical failures by the traders

- represent a challenge to the IPR WTP (such as scaling / bio fouling of membranes, or are known to pass through the RO membrane). 
Development and refinement of the assessment will also be based on comparing results from an ongoing monitoring program at the pilot scale IPR WTP against external water quality standards. There will be a two-year trial of the IPR WTP, and monitoring of 184 hazards will be undertaken verified for increasing understanding of the final water quality and treatment processes. This will involve weekly analysis of microbiological parameters, nutrients, physicochemicals, inorganics, chlorinated solvents and metals, along with quarterly analysis for more exotic and emerging contaminants such as endocrine disruptors, pesticides, radiologicals, pharmaceuticals, DBP and other organics. In addition, auditing of the water quality will be undertaken, taking into account such factors as instrument and process control equipment calibration and maintenance. As part of a coherent strategy to ensure that any future use of an IPR scheme is fully integrated within the water supply business, development of employee training, documentation of methods and procedures used and evaluation of lines of communication will be considered in relation to their contribution to quality assurance in the development of the overall WSP.

\section{Conclusions}

The initial steps of the risk assessment of a process, from description of the system through to characterisation of risks are clearly essential. Understanding the complex composition of the source of water for the IPR system resulted in a heat map which allowed for prioritisation of hazards to a practical level

The approach described for hazard characterisation and risk assessment has been a useful first evaluation of the potential hazards. However, the uncertainty regarding the occurrence of the hazards and their removal, combined with the precautionary approach, results in a relatively large proportion of high risk parameters. 
The IPR WTP was identified as the most sensitive step in the water treatment barrier, although it is important to understand that initial assessments are based on worst-case assumptions in relation to occurrence of hazards, which may have influenced this outcome.

The model of linking failure modes to effect modes and indicators requires further development, however, as part of the WSP it is likely to be advantageous to the management of the system.

\section{Acknowledgments}

This paper reflects the views of the authors who thank Thames Water Utilities Ltd. for supporting this investigation and ADC is grateful to the Mexican Consejo Nacional de Ciencia y Tecnología for PROMEP funding for the PhD scholarship.

\section{REFERENCES}

Asano T., Burton F.L., Leverenz H.L., Tsuchihashi R. and Tchonobanoglous G. (2007). Water Reuse: Issues, Technologies, and Applications. McGraw-Hill, New York, NY.

Bannerman, R.T., Owens, D.W., Dodds, R.B., and Hornewer, N.J., 1993. Sources of pollutants in Wisconsin stormwater. Water Science and Technology 28(3-5), 251-259.

Casani, S. and Knøchel, S. (2002) Application of HACCP to water reuse in the food industry. Food Control 13(4/5), 315-327.

Crook J. and Surampalli R. Y. (1999). Water reclamation and reuse criteria in the U.S., Water Science and Technology 33(10/11), 451-462.

Crook J., MacDonald, J. A. and Trussell R. R. (1999). Potable use of reclaimed water. Journal of the American Water Works Association 91(8), 40-49.

Davison A., Howard G., Stevens M., Callan P., Fewtrell L., Deere D. Bartram J. (2005). Water Safety Plans: Managing drinking-water quality from catchment to consumer. Report WHO/SDE/WSH/05.06, Water Sanitation and Health, Geneva, Switzerland.

Defra, 2002. Water Quality - Urban Waste Water Treatment Directive: Sewage Treatment in the UK: Implementation of the EC Urban Waste Water Treatment Directive. Department for Environment, Food and Rural Affairs, London, UK. 
Del Pino M. P. and Durham B. (1999). Wastewater reuse through dual-membrane processes: Opportunities for sustainable water resources. Desalination 124(1), 271-277.

Dyck, A., Exner, M. and Kramer, A. (2007). Experimental based experiences with the introduction of a water safety plan for a multi-located university clinic and its efficacy according to WHO recommendations. BMC Public Health 2007, 734.

EC (2006). EC Freshwater Fish Directive (2006/44/EC) on the quality of fresh waters needing protection or improvement in order to support fish life. Official Journal of the European Union. 25.9.2006.

EEC (1976). EEC - Water pollution by discharges of certain dangerous substances. Directive (76/464/EEC): Lists I and II.

Environment Agency (2009). Business and Industry Pollution inventory. http://www.environmentagency.gov.uk/homeandleisure/ (accessed April 2009).

Guan, O.K. (2008). Water Safety Plan at Singapore's Water Treatment Plants. Water Safety Plans: Global Experiences and Future Trends. May 12th, 2008. Lisbon, Portugal.

Gurr, C.J. and Reinhard, M., 2006. Harnessing Natural Attenuation of Pharmaceuticals and Hormones in Rivers. Environmental Science and Technology 40(9), 2872-2876.

Hamilton, P.D., Gale, P. and Pollard, S.J.T., 2006. A commentary on recent water safety initiatives in the context of water utility risk management. Environment International, 32(8), 958-966.

IWA (2008). Shaping the research agenda for Water Safety Plans. Workshop in: Water Safety Plans: Global Experiences and Future Trends. 12-16 May 2008, Portugal.

Kasprzyk-Hordern, B., Dinsdale, R.M. and Guwy, A.J., 2008. The occurrence of pharmaceuticals, personal care products, endocrine disruptors and illicit drugs in surface water in South Wales, UK. Water Research, 42(13), 3498-3518.

Metcalf and Eddy (2007) Wastewater Engineering: Treatment and Reuse. 4th edn., McGraw-Hill, New York, NY.

NRC (1998). Issues in Potable Reuse: The Viability of Augmenting Drinking Water Supplies with Reclaimed Water, Volume 1. National Academy Press, Washington, D.C.

NRMMC and EPHC (2006a). Australian Guidelines for Water Recycling: Managing Health and Environmental Risks (Phase 2) Augmentation of Drinking Water Supplies. Natural Resource 
Management Ministerial Committee, Environment Protection and Heritage Council, and the Australian Health Ministers' Conference, Australia.

NRMMC and EPHC (2006b). Australian Guidelines for Water Recycling: Managing Health And Environmental Risks (Phase 1). Natural Resource Management Ministerial Committee, Environment Protection and Heritage Council, and the Australian Health Ministers' Conference, Australia.

NRMMC and EPHC (2006c). Australian Drinking Water Guidelines6. Natural Resource Management Ministerial Committee, Environment Protection and Heritage Council, and the Australian Health Ministers' Conference, Australia.

Rodriguez C., Cook A., Devine B. and Weinstein P. (2007a). A proposed approach for the assessment of chemicals in indirect potable reuse schemes. Journal of Toxicology and Environmental Health A 70(19), 1654-1663.

Rodriguez C., Cook A., Van Buynder P., Devine B. and Weinstein P. (2007b). Screening health risk assessment of micropullutants for indirect potable reuse schemes: a three-tiered approach. Water Science and Technology 56(11), 35-42.

Rodriguez C., Van Buynder P., Lugg R., Blair P., Devine B., Cook A. and Weinstein P. (2009). Indirect potable reuse schemes: A sustainable water supply alternative. Journal of Environmental Research and Public Health 8(6), 1174-1209.

Simazaki, D. (2008). Fulfilling Water Safety through Appropriate Operation and Management of Water Supply System. Water Safety Plans: Global Experiences and Future Trends. May $12^{\text {th }}$, 2008. Lisbon, Portugal.

Singapore Public Utilities Board (PUB) (2002). Singapore Water Reclamation Study: Expert Panel Review and Findings. http://www.pub.gov.sg/newater/AboutNEWater/Documents/review.pdf (accessed March 2010).

Stevenson Ch. and NG B. (1999). Distribution of copper, nickel and zinc in the Thames Estuary. Marine Pollution Bulletin 38(4), 328-331.

WHO, 2005. Water Safety Plans: Managing drinking-water quality from catchment to consumer. World Health Organization, Geneva.

WHO, 2006. Guidelines for Drinking-water Quality: First Addendum to Third Edition, Volume 1, Recommendations. Electronic version for the web. World Health Organization, Geneva. 
Yuan, Y., Hall, K. and Oldham, C., 2001. A preliminary model for predicting heavy metal contaminant loading from an urban catchment. Science of the Total Environment 266(1-3), 299307. 